\title{
My Personal Critical Philosophy The Intersectional Reviewer
}

\section{Libay Linsangan Cantor}

\author{
Takilya ni Leaflens
}

I am a writer by trade, and it is a happy feeling to always get paid writing a piece you worked so hard on, especially now that I work as a freelance content provider for various publishing clients. But out of all the content I have been writing my whole life, there is one kind of writing I will not mind not getting paid to do: film reviews or film criticism essays.

As a film major who graduated from the University of the Philippines' College of Mass Communication, I learned how to analyze films using specific traditions, frameworks, and theories. One of these is the auteur theory, wherein you need to analyze the body of work of a certain filmmaker to compare and contrast past works with the current one you are reviewing. Formalism was, of course, one theory we were required to learn, wherein we need to strictly analyze the technical components of the film in question. We were also taught to review using film semiotics, where we need to investigate the film language presented by the filmmaker, to assess the signs and symbolic structures suggested there.

All of these academic concepts sound very useful when doing school paper reviews or writing academic journal articles, but they may not be very effective for first-time reviewers writing in non-academic commercial publications. Outside of the hallowed halls of academe, you would soon realize that following one strict film analytical theory or framework would 
not really work well with certain readers, especially if you are writing for pop-culture outlets with a general audience. This realization came to me when I started writing film reviews in one of the very first entertainment and lifestyle portals in the country called Localvibe.Com. Author Miguel "Chuck" Syjuco edited and ran that pioneering site with his fellow Ateneans in the late 1990s and early 2000s. He offered me a column of my own which I called "Cut to Cut," and we got varied responses from my reviews. There were times when some readers would react to the very academic tone of my analysis-a tone I did not realize I utilized-and he discussed this nuance with me. He reminded me that we have to address a more general audience whose aim of reading film reviews falls under the lifestyle aspect, that it is also a longer announcement of sorts of currently available entertainment options in the metro. In short, the reviews have to be more relatable. As I wrote material for many similar pop culture-oriented publications in the late 1990s and early 2000s, I soon realized that the tone of my articles and essays needed to be attuned to the style of the publications I am writing for. Therefore, I needed to be more aware of the content outlet's target audience and use language they could understand better. I also realized that I should apply this style to my film reviews as well.

I learned to polish my burgeoning film review style with that first column, and this learning process continued over the years, especially when I started working for Pinoy Times, an "intelligent tabloid” in Filipino established by Philippine Daily Inquirer founder Eugenia Apostol. I was hired to replace their outgoing entertainment editor who merely followed the prevailing gossip-oriented language of local tabloids. When I overhauled the style of our entertainment section-meaning using the traditional journalistic standard of presenting entertainment news as news, not as gossiplike tidbits-I also created a film review column for myself. The column was merely a content filler, actually, when there were slow news days. But I made it into a regular fixture when PR staff of showbiz press conferences (or presscon) organizers started giving me compliments and more tickets to movie premieres of the films they were promoting, saying that they liked my honest no-holds-barred reviews; this meant that I did not merely write 
"praise releases" like other entertainment writers just because I got free tickets to the premiere. I also continued this aspect of not writing praise releases when I was offered a lifestyle section column at the Manila Times (which I called "The Scribe Vibe") in the late 2000s.

But I also got my fair share of criticism for critiquing the way I did. I found out that certain filmmakers would complain because they thought I was merely a tabloid entertainment press person without the proper film credentials. And I did not blame them for thinking this way, though. I read somewhere, ages ago, that ex-Beatles singer-songwriter Paul McCartney allegedly had a snobbish take on music reviews before, since he did not find credible the analysis of reviewers who did not have any musical training or background. For him, they did not have the authority to have a say on things of which he was an expert. But this snobbish take also takes away the power of the audience to appreciate an art form in terms of how they receive or perceive it. In pursuing my M.A. in Creative Writing, I got grounded on reader-response theories that took into consideration the way a particular audience experiences a text. And this could also be applied to films as well, since a film's inevitable audience is not fellow filmmakers but the general populace-a population largely unschooled in the formal traditions of filmmaking.

Aside from my formal B.A. Film education, I indeed had those credentials. I was tempted to remind them of a group of French film critics who took matters into their own hands once, and became filmmakers as well, to prove the points they were making in their analyses. This is why I appreciate the French New Wave filmmakers as well, since I believe you could be both: a reviewer and a filmmaker, at the same time-which is what I actually am, when I reviewed those local films. While I may not have directed full-length films just like them (though I wrote full-length film scripts that actually won awards), I have ample practical knowhow of how to make films-because I made short ones. Outside of my film-school life, I have had the opportunity of writing and directing several short narrative and documentary films, and I have worked as a crew member on the sets of commercial and independent full-length ones. I also became part of several creative development 
groups wherein the primary job was to conceptualize commercial films and TV shows, which we later got to work on as episode scriptwriters. So yes, I was able to work inside film producers' creative offices and on the sets of films or TV shoots, where you experience the chance to see how the material is helmed, from script to screen.

Furthermore, my scriptwriting training did not end in the hallowed halls of academe, either. Having worked as a script analyst for the late director Cirio Santiago's film company, Premiere Entertainment Productions, in the mid-1990s, I also honed my skills in breaking down storylines to see where specific Hollywood influences would seep into the pitched local stories. Santiago made it a point to have me look at the scripts many writers were pitching for possible production. Sadly, on average, four out of five scripts I used to review were downright clones of Hollywood films, and this exercise helped me enhance my skills in comparative analyses of films. After my Premiere stint, I also joined the scriptwriting pools of educational TV shows in ABS-CBN. The very corporate style of creating TV show arcs for specific audiences also enhanced my insider knowledge of how concepts turned into TV shows in this country, to complement my working knowledge of how a film concept becomes a film as well. Needless to say, these job experiences I have had enhanced the way I reviewed films.

During the 2000s, and due to my publication connections back then, I was able to review many types of films for various publishing content needs. Their preference for those reviews was always local titles while some asked for current Hollywood releases. As a personal policy, though, outside of those work-related reviews, I don't really choose what kind of film I will review. My priority wasn't focused on genre or mode of production; I can review MMFF entries, digital independent festival films, foreign films, and commercial releases. As much as possible, I try to review as many films as I could, even if they are not required of me anymore. This was also due to the fact that, after my Localvibe.Com review days, I discovered that many followers of that site read my reviews to gauge whether they would watch a film or not. While that is not my main purpose in writing reviews-to have 
that expert's final say on things-that kind of feedback encouraged me to pursue film criticism more steadily.

My hybrid style of reviewing films apparently struck a chord with readers out there. The first thing I needed to communicate was the relatability of the language I was using. I use words that one would hear used everyday in Metro Manila at a given moment: it has to be friendly, non-alienating (therefore no academic jargon), insightful, and best of all, entertaining. It is not written like a stand-up comic's script, but it's humorous. It is not written like a cynic commenting from the ivory tower, but it is peppered with sarcasm when necessary. It uses terms currently in vogue in mainstream media, popular culture, and society. I was once described by a fellow writer as someone who has this caustic wit about me, so I suppose this is also fused into my writing subconsciously-my own brand of tone or voice. However, writing with this kind of approach in popular publications would easily be dismissed if one did not know the writer's credentials. And since readers-especially those who also echo that ex-Beatles' sentiments-did not have the benefit of looking at my CV, I infuse a hybrid of the auteur and formalist approach of analyzing a film's aspects to give integrity to my observations, with a special focus on the cinematic aspects that always hook me onto a film: the story and scriptwriting, directing, and acting or the (non)believability of casting a celebrity for a role. What, no editing, cinematography, musical score, and others? In a star-struck society like the Philippines', sorry but you have to have some aspects of acting (or their favorite actors) mentioned in there. But yes, the other filmic elements are also there, described or mentioned if they are worth mentioning (meaning if I have not used up my word-count limit yet in breaking down the elements of a film's plotting and storytelling style). This is the line I try to tread when writing for publications back then: one that lies between the academic and the popular or entertaining.

Treading this line for formal publications apparently worked, and I continued getting compliments from friends, peers, and strangers. And this kind of positive response continued when I created a film review blog in the late 2000s called Takilya ni Leaflens (leaflenstakilya.wordpress.com) to continue reviewing films outside of work requirements. But this time, I can 
relax a bit more, and readers can park at their own risk, so to speak, when reading my take of films in my own space. For in this space, I did not need to mind the reputation of the publication I was writing for, since this is my own, and I have my own rules. While I continue to bring with me the academic influences from my Andre Bazin / Sergei Eisenstein / Christian Metz-schooled subconscious and use hybrids of the auteur theory or formalist theory in there, I make it a point not to appear too out there or too up there, as if I am preaching from that ivory tower of scholars. The language is still there, a mix of popular with the academic, but I also code-switch a lot, using Filipino and English interchangeably, especially when I use showbiz or gay lingo sentence formulation or jargon-something that audiences are also exposed to in popular media. I can also amplify my sarcasm, and that caustic wit flies no end here. But to differentiate me from other bloggers, I have always been guided by a small lesson I learned back in Law and the Mass Media class in college that thing called libel. I don't namedrop unnecessarily or directly attack or malign anyone in my films. I understand the fine line between being critical and purely lambasting someone; I never cross this line in my language and tone. But blind items, that's another story!

Blogging about films also found me utilizing theoretical frameworks that appealed to me later in life, namely third-wave feminism, queer theory, and other identity-politics discourses regarding sexual orientation, gender identity and gender expression, or SOGIE. These concepts also work well with film analysis, so that they complemented and enhanced my reviews, which was automatically added to my cognitive reality of an eclectically oriented film reviewer. So no, I do not aim to be feminist in my reviews; it just appears like it, because my feminist self always adds her two cents whenever there's the need to do it. My queer self does the same.

This is the reason I label my approach to film criticism as a hybrid style-I intersect all of these personalities, influences, and work experiences when doing my analysis of a film. Today, I review films as a filmmaker, a scriptwriter, a film studies student and later a film school teacher, a woman, a feminist, an LGBTQ person, a Filipino, and a pop-culture enthusiast. In film analysis, I find it very limiting and myopic to use just one lens in 
looking at things. We already live in a hybrid multimedia/multitasking/ multiple-screen world where many lenses are fused into one, and to analyze a film with a singular theoretical monocle is already passé for me. The intersectionality of who I am gets reflected in the reviews I write.

Writing reviews became a steady hobby for me over the years, and I still publish my reviews in my blog. When I started that film-review blog, I was merely focused on continuing my interest in doing reviews. But as I got older, I also considered the aspect of giving ample feedback to filmmakers as a component of my film criticism, aside from helping to promote certain independent efforts that I believe needed to have wider exposure (such as the works of my friends, colleagues, and former film students). But often, in this country, many filmmakers don't see film reviews as feedback, as I earlier described. Most filmmakers still sadly want reviewers to do a commercial pop-culture pandering, to promote their films and write those praise releases, and they seem to be allergic to the concept of constructive criticism.

Inasmuch as I have been connected with the local showbiz circles since I graduated from college in 1995, I have weaved in and out of the film and TV industries since then, as well as in the publishing industries (lifestyle and entertainment beats of newspapers, and glossy urban magazines). It is inevitable that I find myself becoming friends with or having colleagues from these industries. But when it was time for me to review the films they made, I do it using the intersectional lenses I usually use; I throw in my support, of course, but I also throw in my two cents' worth if I see something that needs to be critiqued. An indie film producer, a former scriptwriting colleague, once chided me, though, for writing a predominantly "negative review" of their gay film, since he was hoping that I would support and promote it just because I happen to be lesbian. A badly made film is a badly made film, first and foremost, and there are no friendships when it comes to film criticism, only honest to goodness constructive criticism. For that producer to feel like I was personally attacking their film and "not being an LGBT ally" goes to show that many filmmakers still need to mature properly in this country. But I will not wait for that; instead, I will just continue assessing films using my aforementioned lenses, friend or no friend. After all, to echo a former gay 
professor-colleague's thoughts about that film, if they wanted us (LGBTQ film reviewers) to write a good film review of their films, then they better make good films to begin with. I concur.

But what is a good film, anyway? In my 20 years of experience doing film criticism for various commercial and academic publications, I have come to realize that it is not proper to critique based solely on the good versus bad dichotomy discourse. I have always lectured in my film/media classes that films need to be assessed whether they are working or not working for a specific audience. An overall storyline could be seen as good, for example, but its specific details may not be working well to tell the narrative it's trying to push. A character might not be working properly in a given subplot, but it may function better in another subplot if her or his story arc leaned towards another direction in the film. As an example, I can use my analysis of That Thing Called Tadhana (published February 16, 2015) which I posted in my blog, the first time a blog of mine accumulated 700+ views during the time it was posted. A look at it now in my blog stats will reveal that this review has had nearly 950 views in all, as of this writing, out of my homepage's 8,339 views.

I mention this post's statistics because there have been several people who shared it and said that they agreed with what I said. There are those who sent me a private message to agree with my points privately instead. The reason for the secrecy is that these readers were afraid to go against the grain of popular opinion about this film. The first item they found far-fetchedwhich they agreed with me when I pointed it out-comprised the unrealistic activities and decisions of the two main characters in this film. Granted that it was attempting to show a unique narrative, but the characters and their situations still need to be grounded in reality-a must for me to consider a film as good. As I mentioned in my review, I found it incredulous for middleclass late-twentysomethings or early-thirtysomethings to just meet someone and spend hard-earned money to go on a whimsical out-of-town trip for several days. Situations of the story need to be plausible for me, or if highly experimental, they should be properly set up; pass on the deus ex machina, please, and hand me the plant and payoff, with dramatic irony on the side, 
anytime. Yes, I will have fries with that. What else? Good, credible acting, one that reflects how a celebrity understood the person they are trying to portray, with the director figuratively walking beside them, philosophically parallel even, guiding them as they step up the ladder of rising action to lead us to a satisfying or thought-provoking climax, plot point by plot point, with the visual assistance of effective cinematography and perfectly pulsed editing and musical scoring. These, to me, are elements that a good movie ought to have.

In teaching scriptwriting and story development, I have always paralleled filmmaking with cooking. It is like saying yes, we all know what ingredients are needed to make an adobo dish, but how can the director, scriptwriter, cinematographer, editor, musical scorer, production designer, actors, and everyone else involved cook up a storm and present us with a new way of preparing the dish? As a filmmaker/scriptwriter, I can detect if they scrimped on the meat, the pepper, or overdid it with the soy sauce or vinegar. My specific senses can taste this filmic dish, so to speak. As an audience member enjoying pop culture fare, I can also sense whether they were trying to make traditional adobo palatable for all, or if they were experimenting gourmet-style, to show us something new, like international film festival new (as I end up asking, "Pang-Cannes ba ito o pang-kanto lang?"). ${ }^{1}$ As a film reviewer, I will assess whether they succeeded in delivering the dish the way they intended to deliver it. I don't mind if they are going the traditional route or the experimental route; I'm more concerned with whether they succeeded in making their project work or not. In short, I assess whether they were able to build a house I would like to inhabit or not.

It does not matter what kind of film I am reviewing, but I apply this approach to whatever it is that I want or need to review. I do not choose specific films to review, after all. I try to enjoy as much as filmmakers could offer out there. I am an avid follower of documentary and narrative films, short or feature-length, and I can review any genre (except for my personal dislike of horror, but I make exceptions based on certain trending films). I do not use any rating system; I merely state the parts of the film that work for me, and I justify my opinion. I do the same with the parts that didn't work 
so well for me; I justify them based on the intersectional lenses I carry as a reviewer.

In general, I find myself labeling a film as well-made when the script has integrity: the story concept is intriguing and unique, the characters are fresh, their characterizations are neither caricatured nor stereotypical, scenes flow logically, and the film directing was able to weave all of these elements into the kind of material that will make you ponder on specific aspects of life that the film is presenting. I used to include great cinematography as another qualifier for a film to be well-made, but even the aesthetics of lighting, framing, and camera movements are subjected to experimenting, making them appear uneven sometimes, so I merely treat it as a bonus if this technical aspect in a film was executed impressively.

As I age with cinema and as cinema ages with me, I still find myself adding new layers to my multi-lensed view of film analysis. I am already at that so-called Tita Stage in my life, ${ }^{2}$ and this is the newest persona who also makes herself apparent in my current film reviews. No, there is no talking down to the younger generation with this approach. It is the opposite; there is always an observation or two (or twenty) of how certain aspects of a film appeal to an older audience, and this is how I let my tita-hood chime in from time to time. This was also how I couched parts of my review for That Thing Called Tadhana mentioned above: a movie-watching tita talking with the future drivers of Philippine cinema.

Now that I have evaluated how I have developed as a film critic or reviewer, perhaps I can safely say that this hybrid style will continue for as long as I have newer personas to add to my being. There will be newer paths to take in life, for sure, and lessons I would gather from such roads might pave the way for newer insights to infuse into critiquing films. In addition, the film industries will also bring you to more paths which you can choose to follow or not. These cinematic travels will always be and remain intersectional. So as an observer I termed as \#filmmiron, ${ }^{3}$ I will always be there at the side of the road, minding signs that say "yield" or moving when the light turns green for me to cross. There will always be new hues and tints, adding on filters or removing older ones, on how I would look and see a cinematic 
spectacle. But my reactions and observations will always remain as eclectic as ever, until the Great Director out there commands me to "roll credits" for good.

Until then, I'll see you all the movies, mga beh. ${ }^{4}$ Over and out-and proud. 


\section{Translations}

1. "Is this for Cannes [Film Festival] or just for the street corner?"

2. "Tita Stage" is literally Aunt Stage, understood as Old (Eccentric) Womanhood.

3. "Filmmiron" is a conflation of "film" and "miron" or kibitzer.

4. Affectionate counterpart for "you guys." Beh, also written bhe, is the contraction of the local approximation for "baby" (be-beh or bey-beh); see also rapbeh, a conflation of sarap (yummy) and beh. 